\title{
unindra
}

Universitas Indraprasta PGRI

Address: Jl. Nangka No. 58 C (TB. Simatupang), Kel. Tanjung Barat, Kec. Jagakarsa, Jakarta Selatan 12530, Indonesia. +62 (021)

7818718 - 78835283; url: www.unindra.ac.id; cultural.syndrome@unindra.ac.id

\section{Nostalgia, Co-creation, and Practice of Design}

Renu Zunjarwad

Arizona State University

Correspondence regarding this article should be addressed to:

Renu Zunjarwad, renumadhav@gmail.com

\section{Article History}

Received : 28-03-2020

Revised : 21-06-2020

Accepted : 04-07-2020

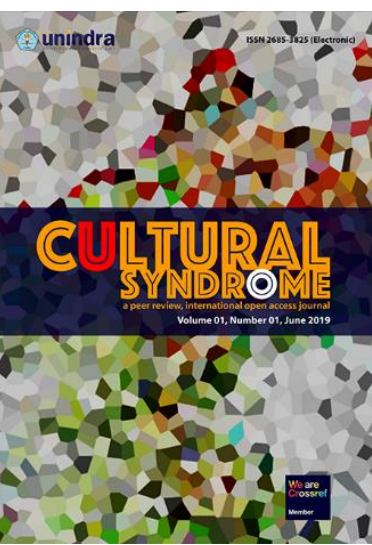

\section{Cultural Syndrome}

a peer review, internasional open access journal e-ISSN: 2685-3825

Editor: iD Ahmad Faiz Muntazori

Publication details, including author guidlines https://journal.unindra.ac.id/index.php/cusy/ about/submissions\#authorGuidelines

\section{How to cite this article (MLA 8th)}

Zunjarwad, Renu. "Nostalgia, Co-creation, and Practice of Design”. Cultural Syndrome, Vol.2, No.1, 2020, pp. 1-19., https://doi.org/10.30998/cs.v2i1.243

The readers can link to article via https://doi.org/10.30998/cs.v2i1.243

\begin{tabular}{ll}
\hline & We are \\
SCROLL DOWN TO READ THIS ARTICLE & Crossref \\
Member
\end{tabular}

Universitas Indraprasta PGRI (as Publisher) makes every effort to ensure the accuracy of all the information (the "Content") contained in the publications. However, we make no representations or warranties whatsoever as to the accuracy, completeness, or suitability for any purpose of the Content. Any opinions and views expressed in this publication are the opinions and views of the authors, and are not the views of or endorsed by Universitas Indraprasta PGRI. The accuracy of the Content should not be relied upon and should be independently verified with primary sources of information.

\section{(c) $(1)(9$}

This work is licensed under a Creative Commons Attribution-NonCommercial 4.0 International License.

Copyright by Renu Zunjarwad (2020)

The authors whose names are listed in this manuscript declared that they have NO affiliations with or involvement in any organization or entity with any financial interest (such as honoraria; educational grants; participation in speakers' bureaus; membership, employment, consul tancies, stock ownership, or other equity interest; and expert testimony or patent-licensing arrangements), or non-financial interest (such as personal or professional relationships, affiliations, knowledge or beliefs) in the subject matter or materials discussed in this manuscript. This statement is signed by all the authors to indicate agreement that the all information in this article is true and correct 


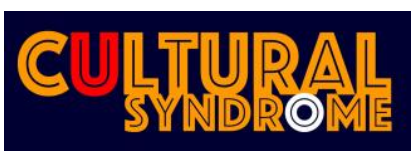

Vol.2, No.1, 2020, pp. 01-19

e-ISSN: 2685-3825

https://doi.org/10.30998/cs.v2i1.243

\title{
Nostalgia, Co-creation, and Practice of Design
}

\author{
Renu Zunjarwad \\ Arizona State University
}

\begin{abstract}
The study proposes that a form of research design integrating co-creation, interviews, and visual analysis can effectively operationalize challenging concepts of evoking gastronomic nostalgia and place identity surrounding ethnic food artifacts. This inquiry employs an example of Mumbai's street foods to examine consumption, production, and distribution practices by comparing the cities of Mumbai, India, and Phoenix, United States. Rigorous qualitative analysis of the data gathered from fourteen Indian immigrants in Phoenix suggested that compared to Mumbai, consumption of street foods radically declined as street foods' core identity shifted in Phoenix. Further examination discovered that the differences in having street foods in sit-down settings or the lack of a public street food culture might never be bridged in Phoenix. However, specific production and distribution strategies rooted in nostalgic memories from Mumbai may boost consumption.
\end{abstract}

Keywords: nostalgia, co-creation, ethnic food artifacts, visual design research

Correspondence author: Renu Zunjarwad., renumadhav@gmail.com, Chicago, United States

(c) (i) (s)

This work is licensed under a CC-BY-NC

\section{Introduction}

Food is a cultural construct with deep roots in history, context, and society. The sensuality of eating can trigger powerful rapid cues mainly through tastes, smells, and sometimes through visual representation. Food carries a lot of symbolic, emotional, sensorial, and socio-cultural significance. Therefore, gastronomic nostalgia can be employed as an effective medium by researchers to make sense of the past, the present, and discover future opportunities. In order to demonstrate the idea, this study used the example of Mumbai's celebrated street food artifacts and examined the making, eating, circulating, and experiencing the foods in the context of transnationalism. By comparing these practices in the cities of Mumbai, India and Phoenix, USA, the author investigated the influence of nostalgia on consumption, production, and distribution practices 
amongst the Indian immigrants in the United States and explored how the practice of design can participate in fashioning the street food experiences. The work presented here is the part of a larger Ph.D. dissertation that examines how nostalgia, authenticity, and tradition shape Indian street food practices. Here the focus is solely on nostalgia.

The examination of Mumbai's street foods disclosed that the deep-seated values of Mumbai's street foods shifted when the foods re-territorialized in Phoenix, which resulted in lowering the consumption. Nostalgia, as remarkable experience and expression in participants' lives led to the development of specific practices and the emergence of certain trends.

The research pointed out that the methodological approach that included cocreation, extensive visual research, and follow-up interviews was mostly successful because of the comparative nature of this work. The main focus here is to discuss cocreation tools, methods, their planning, implementation, analysis, strengths, and weaknesses when used to examine design artifacts, especially the foods. The aim here is also to promote methodological rigor and critical domain knowledge in the field of design.

\section{The comparative contexts of Mumbai and Phoenix}

Mumbai's street foods as edible culinary artifacts have evolved over hundreds of years and exhibit a unique cultural and culinary heritage. The foods are the city's lifeline and are locally made, resourced, consumed, distributed, and exist within its meanings of network rooted in socio-cultural, economic, psychological, behavioral, symbolic, and historical contexts. For instance, Mumbai's famous specialty bun, pav was first introduced by the Portuguese in the late 15th century when they ruled Mumbai and parts of India. Today pav is the primary ingredient in most of the Mumbai street foods. British- led Industrial Revolution in the 18th century generated massive regional migration with people bringing their local culinary traditions to Mumbai from southern, western, and northern states and cities of India. The rise of Industrial activity steered the emergence of a proletarian-style diet-a diet of factory workers that later inspired Mumbai's cosmopolitan street food culture. Today, Mumbai is a home of many thousands of street food stalls conveniently located around schools, offices, colleges, public places, train stations, and residential areas with easy walking access.

Phoenix, on the contrary, is amongst the least walkable cities in the US (KTAR.COM). Street food culture is nonexistent and Indian restaurants serve the foods in sit down and formal settings. Unlike Mumbai, the Indian community's Phoenix heritage can be traced back only a handful of decades because Indian immigration to Phoenix substantially grew only after the liberalization of India's economy in 1991 and the growth of IT sector. Thus, though the cities of Mumbai and Phoenix are globes apart, they share a mutual backdrop of migration, which makes them perfect contenders for comparative research. Holtzman (365) pointed out that food provides a particularly rich arena to explore memory's complexities. Hence examining nostalgia can offer a profound opportunity to make sense of entwined connections between memory, Mumbai's street foods, cultural practices, transnationalism, and the field of design. 


\section{Methods}

The main research questions this study attempts to address are: What role has nostalgia played in shaping consumption, production, and distribution of Indian street foods in the context of globalization? How can the practice of design participate in fashioning the street food experiences transnationally? To explore these questions, author implemented the methods of co-creation, group interviews, and visual research. First, let's understand why focus on nostalgia is critical here.

\section{Why "nostalgia"?}

Nostalgia comes from the Greek word nostos, means "return home," and algia, meaning pain or longing. Thus, nostalgia literally means "homesickness." Swiss physician Johannes Hofer first coined the term nostalgia referring to it as a disease and identified persistent thoughts about home, melancholy, insomnia, anorexia, weakness, anxiety, lack of breath, and palpations of the heart as the symptoms of nostalgia (McCann). The definition of nostalgia as a disease prevailed until the late nineteenth century when it was de-medicalized, leading to the shift of nostalgia from being a pathological disorder to an emotion of wistful longing for the past. Today nostalgia is considered as an emotion (Wilson).

There are a couple of reasons why the focus on nostalgia is vital for the instigation and inception of place-identity and memory. First is the comparative and transnational nature of this inquiry. Transnationalism emphasizes immigrants developing and maintaining familial, economic, social, and political connections that span across borders (Schiller et al.). "Transnationalists" or immigrants bring their culture with them when they immigrate to a new country. Culture is the order of life in which human beings construct meanings through practices of symbolic representation (Appadurai; Crowther; Inda and Rosaldo). Thus, culture goes where the subjects and objects carry it along and is reshaped as it settles in a new context and location, which is called "reterritorialization" of culture (Inda and Rosaldo). In this study, Mumbai, India is the homeland and Phoenix in Arizona, United States is the place of migration.

The second focus here is the context of food. Food studies from the past emphasize food-centered nostalgia and the experience of displacement. Nostalgia can prompt and excite several different senses. Some examples are:

1. Sentimentality for a lost past, viewing food as a medium to recollect memories of childhood and family (Mankekar)

2. Bodily memories of specific flavors, dining contexts, eating, cooking, and serving styles (Chen; Holtzman; Sutton)

3. Embodied memories of comfort foods, holiday rituals, and family recipes (Jones and Long)

The sensorial and nostalgic moments related to traditional foods have been extensively discussed by scholars from many disciplines. Seremetakis (3) talks about how memories of tastes and smells of Greek sour grapes and Aphrodite peaches emerged in exile and provided a temporary return to a time back in the homeland when 
she consumed them regularly. The theme of gustatory nostalgia is particularly evident in Mankekar (200) study of transnational circulation of public cultures -between India and the U.S. - through images and commodities found in Indian grocery stores in San Francisco. She argues these grocery stores participated in the consumption of discourses of the homeland and the goods purchased by Indian shoppers fostered historically validated forms of identity. Ray (35) places food at the center to study changes in everyday food practices that are shaped by immigration among Bengali-American households and emphasizes the ways by which food becomes a nexus of nostalgia and cultural identity.

Above discussion highlights nostalgia as a profound feeling and expression for foods and beyond, and as Wilson (25) argued it could be used as a cultural commodity derived from the experience of a particular age-cohort and transformed into a market segment. Wilson (26) suggested, "What we are nostalgic for reveals what we value, what we deem worthwhile and important. Hence, nostalgia could be very valuable in helping us figure out what people want". The field of design has used nostalgia as a secret weapon to appeal to customers (Huppatz; Xue and Woolley). In 2012, Subaru launched FirstCarStory.com, an online marketing campaign, in an effort to gather peoples' firstcar memories and launch the 2012 Subaru Impreza car. Alan Bethke, Subaru's then Marketing Communications Director highlighted, "First-car stories are often the most memorable stories we have," he continued, "The First Car Story Campaign provides a creative outlet for reliving those unique, funny, unforgettable car experiences for anyone who had a first car can relate to" (Baar).

Another example that emphasizes the use of nostalgia to promote the brand is Harley Davidson's reaffirmation of its 1950s and 1960s Springer Softail and Heritage Softail Classic models in late 1980s. Nostalgia has played an essential role in shaping production and consumption of design artifacts throughout the 20th century and has continued to do so in the 21st century. Thus, nostalgia is about interpreting what was valued in the past to create meaningful future opportunities and co-creation as a method can reinforce that sensemaking process.

\section{Definition and significance of the process of "Co-Creation"}

Co-creation is one of the important generative research techniques in the field of design (Hanington; Holroyd; Kumar; Steen et al.; Weiler et al.; Wilson and Zamberlan). Sanders and Jan Stappers (52-53) discussed the effectiveness of generative methods as a part of participatory research in design. They emphasized its high value in reaching participants' tacit knowledge-thoughts that are known but cannot be verbally expressed-and latent knowledge-ideas that have not been experienced yet but the exploration can lead to creating future opportunities. The main concept here is to facilitate expressions of casual and difficult-to-reach experiences, views, memories, emotions, and feelings through collaboration and creativity.

For instance, The Institute Without Boundaries (IWB) at the School of Design at George Brown College in Toronto conducted a project with the Municipality of Lata in Chile to explore possibilities for redesigning the city after recent natural disasters. The 
research was done in collaboration with the design students from School of Industrial Design at Carleton University, Ottawa, Canada, and DuocUC in Concepcion, Chile. Before the weeklong research sessions with the participants, students spent time as a group working to establish meaningful ways to communicate and guide the participants through the research process. They created Lata-specific generative toolkits for thirteenyear-old student participants from schools in Lata that consisted of word-sets, pictures, stickers, and stationary materials.

At the time of the sessions, "What do you like about Lata?" was explored as the main research question, and the children created collages to map their ideas, many of which highlighted stories of the recent severe earthquake and included words related to family, parks, beaches, food, and more. After the "making" activities, participants shared the stories behind their collages and maps. The last step was the group interviews, which led to a deeper discussion about the participatory work and the future re-design possibilities for the city of Lata. Researchers closely paid attention to body language, facial expressions, and vocal tone while seeking to understand children's stories and the interview question answers (Sanders and Jan Stappers 92).

Generative techniques usually result in the creation of an artifact that revolves around the topics, like recalling memories, expressing feelings, connecting dots, and imagining the future to name a few. The toolkits act as a vehicle to help generate such complex information used through artifacts and the associated stories and, hence, should be developed and designed carefully, insisted Sanders and Jan Stappers (93). They suggested incorporating the aspects of dimensionality $-2 \mathrm{D}$ and 3D materials; contentcognitive and functional, as well as emotional and expressive; and lastly the concept of time, which can reveal how a single event or events unfolded. Some of the examples of the toolkits are: emotional toolkits that can include photos, images, and words for eliciting memories; storyline toolkits that are designed to optimize the expression of a story; or cognitive toolkits that are designed to help understand the connections between the points.

The data collected through say-do-make techniques, associated interviews, discussion sessions, and focus groups can be analyzed using qualitative methods of coding. Quantitative tools like multi-dimensional scaling can be used to identify relationships between items used to create the artifacts (Sanders and Jan Stappers 122). Mixed methods of content analysis looking for clusters, patterns, and themes are also useful.

While discussing the possible limitations of the generative research approach, Hanington (12) cautioned that the rigor involved in analyzing creative information should not be compromised in any case. These techniques are time-consuming and demand extensive work from conception through analysis. Another challenge is to avoid potential bias involved in the pre-selection of the toolkit materials. Consistency in the procedure of conducting multiple sessions needs to be observed and demands refining of the toolkits, methods, and the processes through several pilot and practice sessions.

Co-creation has pros and cons; however, the above discussion explains why cocreation is an effective method to explore memories and nostalgic encounters 
surrounding Mumbai's street foods. With foods being multi-dimensional and complex experiences, background research established that co-creation and creativity could enthuse the array of emotions, recollections, expressions, and perspectives as participants would make collages and share street food stories. Such efforts would significantly contribute in acquiring intriguing responses and information from the participants. Thus, focus on nostalgia, ethnic food artifacts, and emphasis on integrating methodological rigor led to the choice of co-creation.

\section{Sampling strategy}

Thirteen Indian immigrants living in Phoenix participated in this study. All of them lived in Mumbai as children and adolescents and migrated to the United States in their early or late 20s for work, higher education, or because of marriage. Out of 13, six participants - three women and three men, all between 32 to 50 years of age-were living in Phoenix between eight to 20 years at the time of their participation. The remaining seven participants - four women and three men, all in their early to mid-20s-migrated to Phoenix for higher education and had lived in the US for less than two years at the time of their participation. To get additional perspective on Indian food production, regulation, and related practices, author also interviewed a Phoenix-based former restaurant owner, an Indian immigrant himself.

Author approached participants through personal and professional connections and recruited using a combination of purposeful and snowball sampling. It was a twostep process. Once identified, the participants were contacted over the phone to explain the research project and the process. After the participants expressed interest, author emailed them a brief questionnaire to confirm their backgrounds, including questions about the name of the Mumbai suburb where they grew up, the reason and year of migration, the number of years spent in the US and Phoenix, and more. The author maintained the diversity of sampling by choosing participants who had been living in Phoenix from a few days to 15-20 years. Recruiting process emphasized on enlisting participants who grew up in different suburbs in Mumbai to diversify the knowledge of experiences.

\section{Method 1: Co-Creation}

13 Indian immigrants participated in groups of 3 or 4 and were part of group interviews. Groups were as follows:

Group 1: Participants A, B, and C (all men who lived in the US for more than 8 years) Group 2: Participants D, E, and F (all women who lived in the US for more than 8 years) Group 3: Participants G, H, and I (all men who lived in the US for less than two years) Group 4: Participants J, K, L, and M (all women who lived in the US for less than two years)

One-hour long group interviews were conducted immediately after the co-creation sessions. Altogether, each session of co-creation and interviews was around 4 to 4.5 hours long.

1. Getting ready 
The purpose of the sessions was mainly to trigger memories related to street food experiences in Mumbai and Phoenix. Hence, three identical emotional toolkits included numerous laminated photos of street foods sold in Mumbai and Phoenix, as well as contextual images like public transportation options of local trains, city buses, and auto-rickshaws in Mumbai since they are a sustenance of everyday life in the city. The toolkits also included a variety of stickers like emoticons, picture icons, and images of activities related to street food consumption, production, regulation, and hygiene.

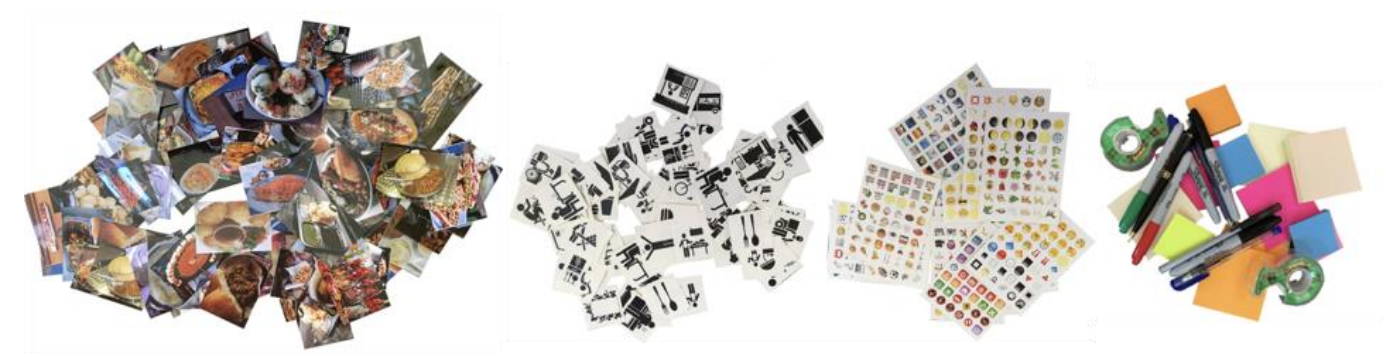

Figure 1. Elements of emotional toolkits provided to the participants

2. Set up

All four group sessions were hosted at author's home for convenience of setting up cameras and audio recorders and to offer a homely environment to the participants to motivate richer conversations. Author served Indian street foods like samosas and vadas to stimulate food-related memories and initiate correlated conversations.

3. Implementation

The generative research method of co-creation involved making collages, journey maps, and explaining the stories behind them. Each participant received the following set of printed instructions (see Figure 2) before starting the session. Author verbally repeated, elaborated on those instructions, and addressed participants' concerns and questions.

4. Good/bad collage

The first step was a group activity to create a good/bad collage focusing on participants' past street food experiences from when they lived in Mumbai. They received a large blank sheet of a paper with only an empty circle printed on it. Participants used Post-it notes to write their points and placed good experiences inside and bad experiences outside the circle (see Figure 3). 
1. Good/bad Stuff

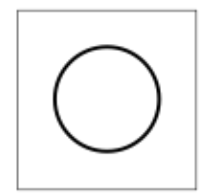

Hints: Group activity

Good inside $\bigcirc$

Bad outside $\bigcirc$
2. India Collage

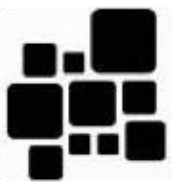

Hints: Individual activity

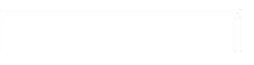

Think about places, foods, surroundings, emotional states, sounds, flavors, aromas, visua memories, people etc.
3. Phoenix Collage

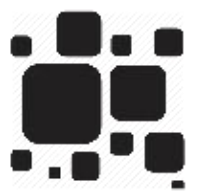

Hints: Group activity

\section{Thing about placos, foods, \\ Think about places, foods,} surroundings, emotional states, sounds, flavors, aromas, visua memories, people etc.
3. Share...

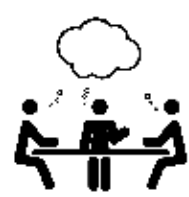

Hints: Group activity

Elaborate your collages Discuss street food $(2)$
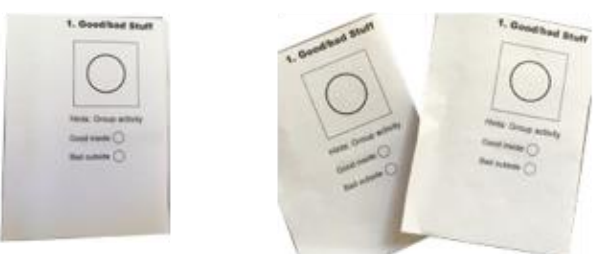

Figure 2. A printed set of instructions that I shared with participants

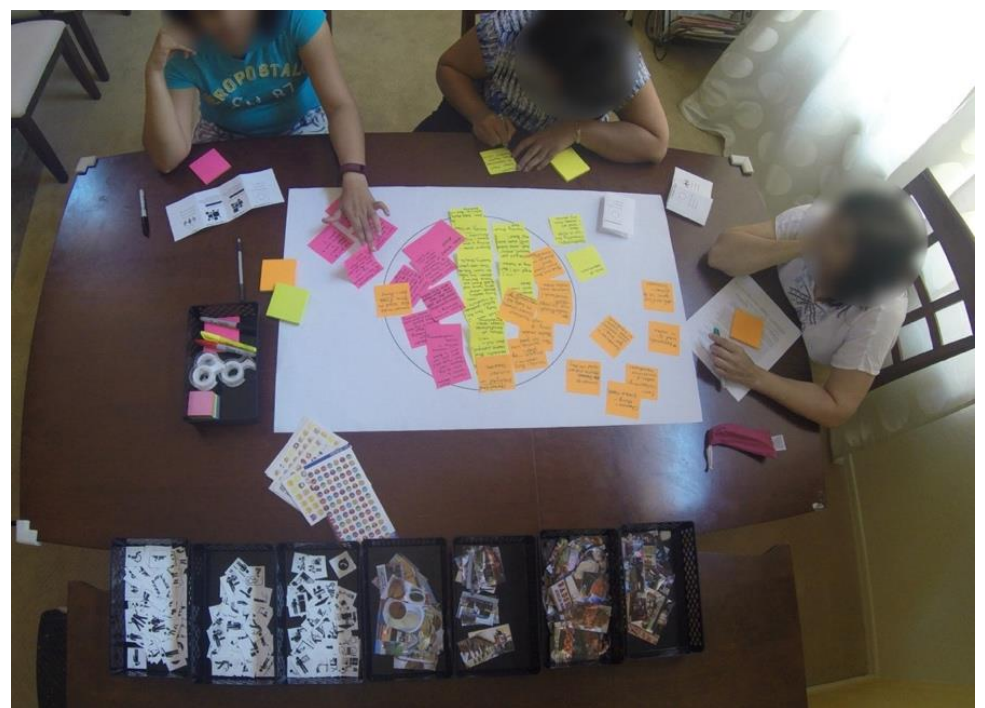

Figure 3. Group 2 participants working on Good/Bad collage

5. India and Phoenix collages

The second step was India collage, and it was an individual activity. Literature research revealed vastness of street food practices in Mumbai. Hence, to know about broad range of Mumbai's street food experiences, creating India collages was an individual activity. Each participant was asked to remember one experience and create a journey map to visually explain how that experience emerged, progressed, and ended. The expectation was to think about every detail including the environment, interactions, aromas, tastes, the process of ordering, serving the food, etc. They could use all elements of the emotional toolkits here to visually express the whole story (see Figure 4). 

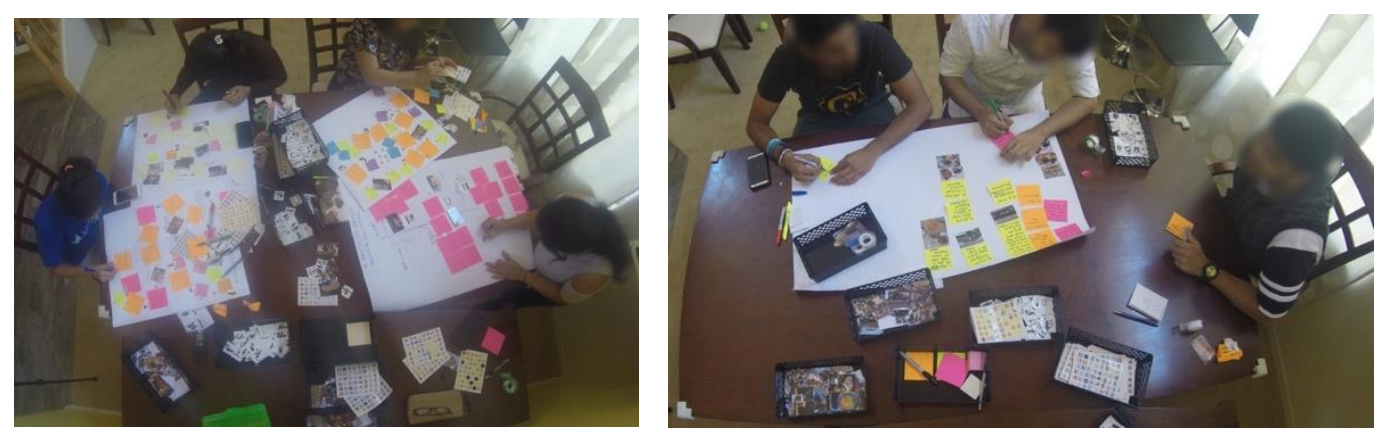

Figure 4. Group 4 participants working on the India and Phoenix collages

Literature and research pointed at smaller scale of Indian street food culture in Phoenix, hence making phoenix collages, which was the third step, was a group activity (see Figure 4). Each group created a collage of their typical Indian street food experience from Phoenix - how and why they decide to go to eat Indian street foods, how they travel to the restaurants, the company included, the food they order, and anything else about those experiences.

\section{Method 2: Group interviews}

The semi-structured group interview questionnaire explored past street food experiences from Mumbai, how that changed when participants moved to Phoenix, what happened in their recent India trip when they had street foods, and how they would compare that experience in Mumbai with Phoenix. Participants also answered questions about their ideal street food experiences in Mumbai and Phoenix and shared their viewpoints about how the street food culture could evolve in both places in future.

\section{Method 3: Visual research}

All co-creation sessions were video, and audio documented. The GoPro camera captured top-down angles, and the author implemented the technique of continuous monitoring to collect unobstructed data related to body movements in space, nonverbal interactions, and physical actions. Still images were captured on DSLR and cell phone cameras (see Figure 6), record interviews, and visually document all other activities. The ability to gather visual data from different vantage points diversified data capturing and strengthened the quality of information.

\section{Testing the tools}

Given the technological complexity, testing was crucial. Before starting fieldwork, the author conducted a five-day long participant observational study at a local Indian restaurant in Phoenix and tested the visual data collection toolkit and approaches. That experience significantly helped in understanding the nuts and bolts of the multitasking necessary for documenting field notes and managing equipment while conducting participant observation fieldwork. The first co-creation session as a pilot helped to finetune interview questionnaires, probing techniques, and skills for conducting and managing group activity. Similarly, early fieldwork sessions in Mumbai facilitated an 
improved understanding of specific onsite challenges and knowledge of developing successful strategies to address them.

\section{Data analysis}

All video, images, textual, and audio data were analyzed qualitatively using the technique of open coding and MAXQDA software. All interviews were transcribed as texts and use of MAXQDA offered the convenient option to code images and GoPro videos directly (see Figure 5). Each document, image, and video went through at least two cycles of open coding. The first two or three transcriptions consumed four to five cycles of coding because of the process of finalizing the codes. After coding, the next step was to generate themes and write analytical memos, which happened as coding progressed. Analytical memos acted as a crucial connection between data and theory.

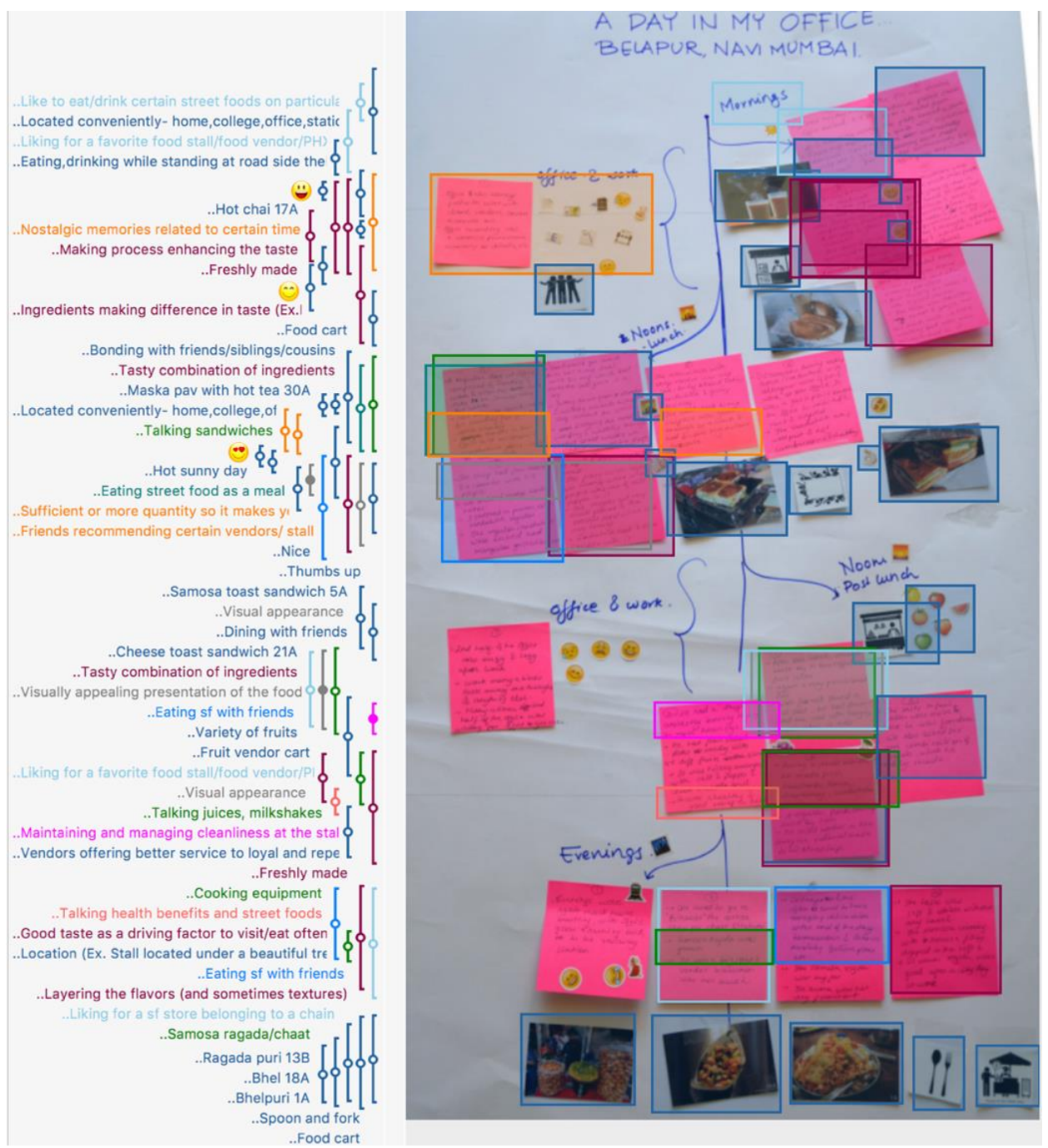

Figure 5: Example of coding of India collage in MAXQDA

\section{Results and Discussion}


Author discovered that Mumbai always remained a part of the participants' lives, no matter where they lived. For them, the foods, the vendors, the tastes, the aromas, and the experience together interweaved a piece of laced art with a perfect equipoise-loosen a thread and nothing will be immaculate anymore. Mumbai, as a dominant culture established the original meanings and central values of the street food culture. Phoenix was the adopted home for Mumbaikar (People of Mumbai) migrants, where the street foods were re-territorialized within the local culture. Figure 6 juxtaposes how the founding values of street food culture and the experience transformed when Mumbai's street foods arrived in Phoenix. Mumbai's signature spicy, tangy, sweet, sour, and hot palates and the central values of convenience, affordability, consistency, creativity, informality, and cordiality diminished when the street foods settled in Phoenix. Local cultural influences, standardized tastes, and efforts to reach beyond the Indian community, as well as a polished, exotic, and formal treatment of the street foods, distorted the associated meanings. These findings and the insights related to the founding values (from Figure 6) emerged from the part of author's Ph.D. research that focused on authenticity and tradition and employed historical, qualitative, and rapid ethnographic research approaches.

Co-creation participants perceived experiences in the two cities to be distinct and couldn't fathom the thought of sitting in a restaurant to eat street foods, which they grew up enjoying at the roadside stalls in Mumbai in a highly social environment. Participants expressed that spending time with friends and family while feasting on favorite street foods was a tradition in Mumbai through collages and discussions (see Figure 7). The shift in approach and the environment drove the interest down.

Research revealed that Mumbai's street foods had a distinctive identity, which was unique to its local context. Unlike many Indian recipes of curries and rice, for example, that could be reproduced in Phoenix restaurants, Mumbai's street foods without the archetypical characteristics lost their appeal. Mumbai's street foods were tightly embedded within a close nit web of values and inherent meanings that emerged, evolved, and fitted locally. When the foods were re-territorialized in Phoenix, the Mumbai migrants couldn't embrace them. The result was the emergence of a wholly new and different ethnic food culture, which meant new tastes and new practices that were specific to Phoenix (see Figure 6). Mumbai, as a primary source, was a story of a distinct street food experience rooted in unique consumption, distribution, and production practices. It represented diversity and creativity but not much of regularity when it came to the governance, hygiene, and sanitation practices.

In Mumbai, vendors had complete freedom to design food stalls innovate food preparation and serving options and had a lot more control over how they wanted to run their businesses. Phoenix, on the other end, had a more significant presence of production practices administrated by strict regulation policies, which lowered creativity and that impacted consumption. Some examples of stringent policies were rigid standardization of design and arrangement of the kitchen, and strict sanitation procedures related to food preparation and serving by Phoenix's Department of Public Health. Such practices limited diversity and creativity. It also pushed the restaurant 
owners to pay the highest attention to managing and maintaining required hygiene and cleanliness standards, which limited efforts invested in the creation of tastes and foods.

However, Mumbai remained an essential source of inspiration and the only backward correlation between Phoenix and Mumbai was enhanced expectation for hygiene. When immigrant participants visited Mumbai, they desired higher standards of cleanliness and sanitation. This expectation was stronger in older participants who had lived in Phoenix for 10 years or more.

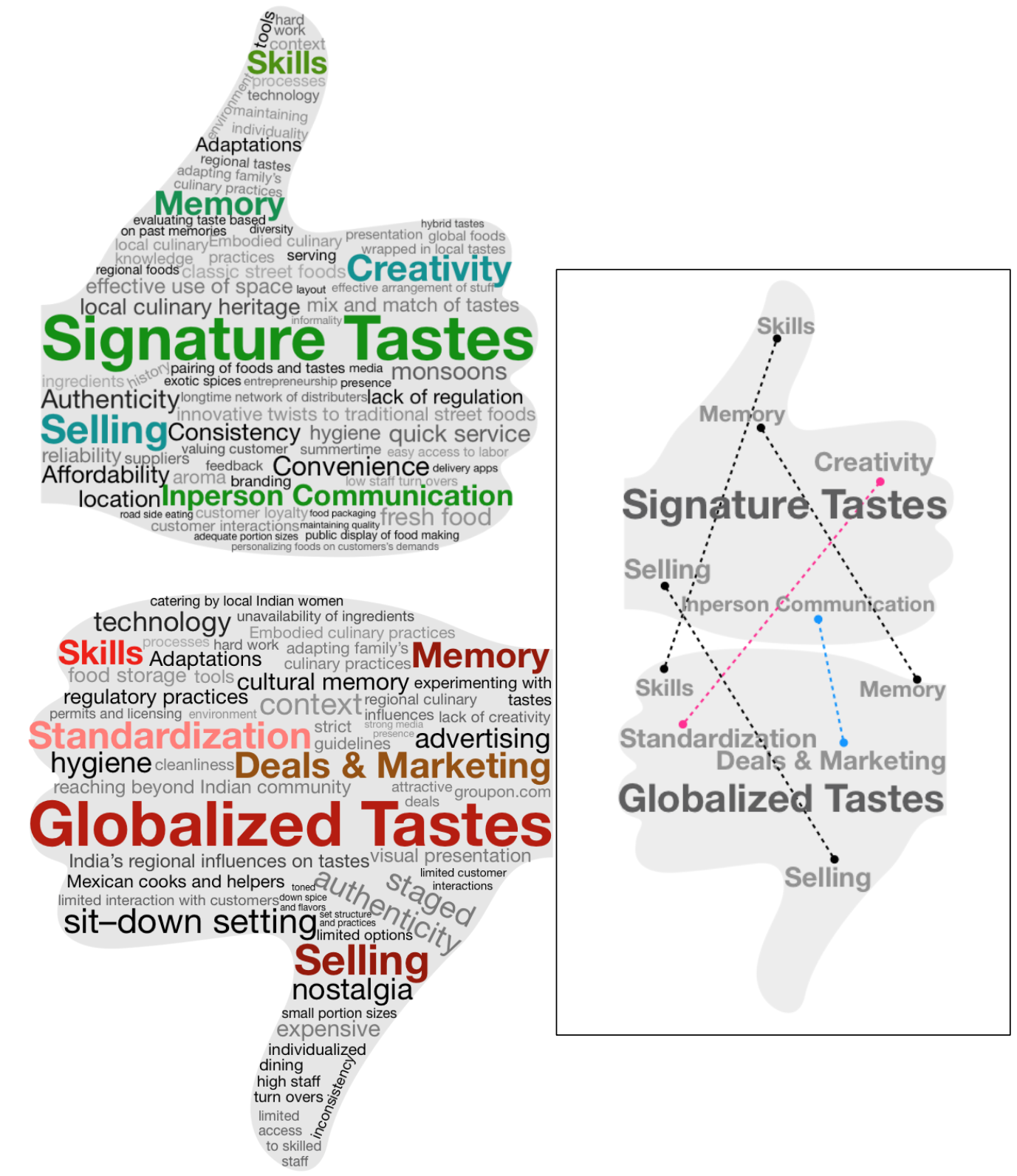

Figure 6. Comparing Mumbai and Phoenix cultural and culinary landscapes

In Mumbai, the elements of consumption, production, distribution, and representation couldn't be separated to be distinct. Mumbai's cultural model showcased a balance and harmony through an intricate co-relation between the various practices. 
All parts together played a crucial role in producing a vibrant image of uniqueness. In Phoenix's cultural model, however, the balance was off-center, and production was more about regulation than distribution and consumption.

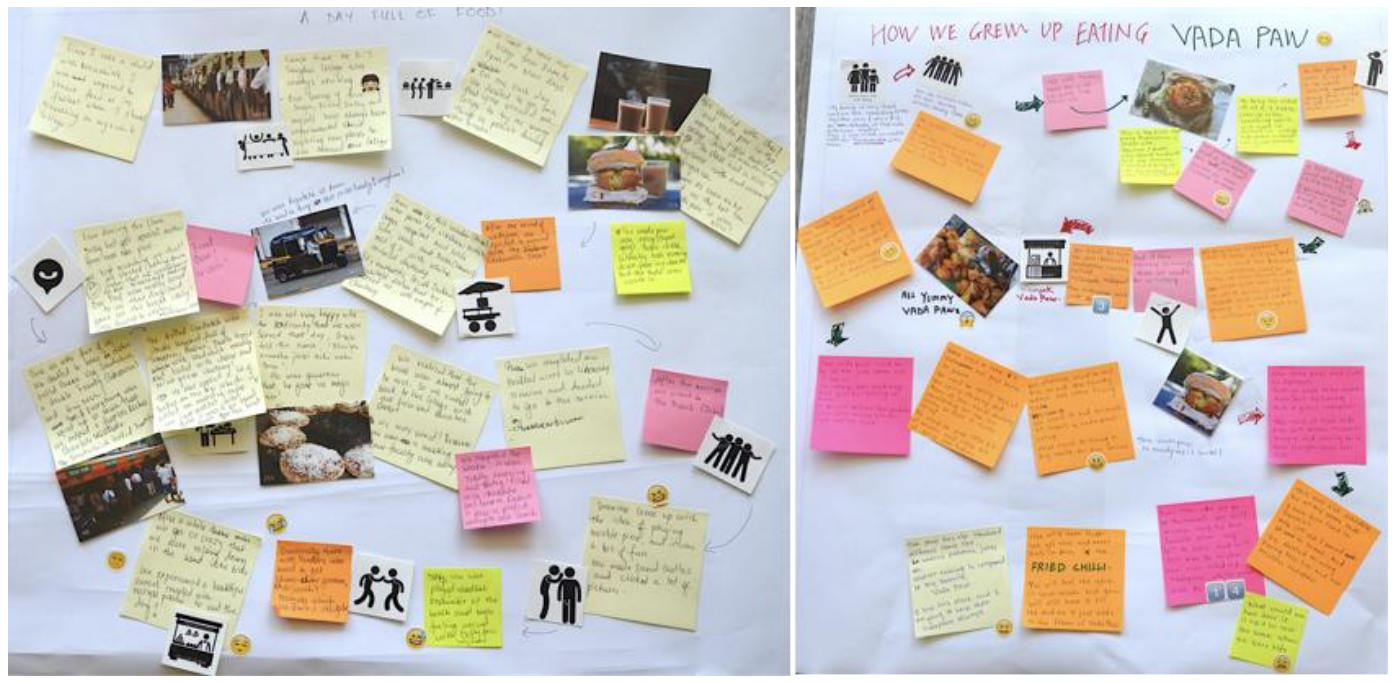

Figure 7. Couple of examples of India collages by the participants

\section{How participants expressed nostalgia?}

The most common expressions for participants were closing eyes and nodding heads, sighing, smiling, disappointed tones, and vivid descriptions of foods and preparation processes accompanied with smiles and hand movements. Research revealed a typical step-by-step pattern of food memory-related exchanges during cocreation sessions. The first step was any one participant mentioning the name of a Mumbai stall or the food in an excited voice while working on collages. The next step would be the collective responses of astonishment or admiration for that food or stall. Other participants rarely contradicted or reacted negatively. The positive reaction would encourage the first person to share details and stories of tastes, flavors, stall, vendor, or food making processes. Author observed that while sharing stories, participants used a series of expressions that included yearning, nodding, romanticizing, hand movements, and sometimes a dash of a loss on the face. The emotional reactions would lead to the fourth step of group mates jumping into the conversation to add their stories of favorite foods and vendors and, thus, developing a chain of reminiscences.

The above step-by-step pattern reveals a complex intertwining of individual and collective participation and verbal and non-verbal communications. It points to the highly interactive and social nature of street food consumption. Nostalgic expressions revealed how participants separated collective and individual partaking. At individual levels, participants discussed personal memories related to the street foods; such as participant D's parents not allowing her to eat street foods when she was young or participant H's mother encouraging him and his sister to snack on street foods because she preferred cooking only for lunch and dinner. But these individual food experiences were wrapped within larger collective memories of tastes, foods, friendships, and love 
for Mumbai's unique food culture. That is what mainly shaped consumption, production, and distribution practices.

Sensorial, seasonal, and special occasion memories

Participants spoke about a variety of food experiences for the good/bad collage they had more to say about tastes and flavors than aromas or food presentation. But when the participants had the opportunity to discuss a single experience in depth for the India collage, they added details about the aromas and food presentation. The sensorial experience of smell was also prominent when participants talked about waiting for the food or as an immediate reaction when the food order arrived (see Figure 7).

Research suggested that since participants liked street foods in Mumbai more than those sold at Phoenix restaurants, they were more observant and responsive to the aromas, flavors, and sounds related to Mumbai street foods. They exhibited significantly higher interest in remembering, discussing, and indulging in talks about tastes, aromas, flavors, fragrances, visual appearances, and sounds related to the street foods in Mumbai. One aspect that emerged from the research was about participants feeling nostalgic for Mumbai's hot and spicy street foods of kandabhaji, vada pav, and cutting chai during Monsoons. It was a complex yet exciting feeling and an example of how participants experienced deep psychological and emotional connection with Mumbai though they lived in Phoenix. Participants I and G from group 3 spoke about making kandabhaji with their roommates in Phoenix on a rainy day.

Special occasions, such as festivals, birthdays, and family events, triggered street food memories. Participants remembered celebrating with friends and family over favorite foods at preferred stalls. Participant $\mathrm{H}$ talked about having jalebi every year on August 15th, the Independence Day of India. Participants K and J discussed feeling nostalgic for favorite foods on festivals which triggered a visit to Little India store and café in Phoenix.

\section{Role of media}

Participant J spoke about one of her latest experiences of intensely missing her favorite jini dosa. She was feeling overly nostalgic and spent hours watching videos of jini dosa on YouTube. She shared that she ended up going to Little India with her husband that evening "just to calm her taste buds down." Little India neither sold jini dosa nor offered the tastes that participant J loved back in Mumbai, but as she said, it temporarily tamed her food desires. It was a typical experience shared by many participants that they accessed Google and YouTube for street food recipes and videos. Participant G shared the story of his first experience of making dosa from scratch by referring to an online recipe and feeling accomplished for his achievement after successfully making it at his Phoenix apartment.

Restaurateurs in Phoenix viewed nostalgia as a strategic tactic and consciously incorporated specific traditional practices to promote their businesses. They carefully orchestrated online and social media presence. $\mathrm{N}$, the restaurant owner in Phoenix 
advertised special treats of kandabhaji, samosas, vada pav, and ginger chai on his restaurant, Pastries N Chaat's Facebook page the day it drizzled or got cloudy.

Playing Hindi Bollywood music at the restaurants and decorating the dining spaces with Indian artifacts were the most common practices to emphasize the sense of belonging. Author observed that some restaurants in Phoenix advertised selling "Bombay chaat" and "Mumbai's famous vada pav" on their menu. Thus, nostalgia uniquely shaped production practices in Phoenix, and the restaurant owners used the expression for their advantage to stand out in competition.

\section{Conclusion}

The research here identified that in Phoenix Indian street foods deflect too far from original tastes, which results in customers rejecting the foods. The differences of having street foods in sit-down settings or the lack of a public street food culture might never be bridged in Phoenix. However, specific strategies like offering complimentary treats, tailored foods, investing in building appreciated flavors and tastes, better vendorconsumer interaction, higher reliability, and consistency may help to raise the Indian customers' interest.

This inquiry implemented a practice-based research approach to examine a food artifact of ethnic street foods. It emphasized the significance of focusing on cultural networks of an artifact to make sense of associated meanings and practices in global context. Many scholars have highlighted the need for focusing on complex global and cultural facets in design and this research attempted to address that gap (Boradkar 275; Buchanan 15; du Gay et al.; Friedman 208; Rittel). In the process, the inquiry presented detailed knowledge about design and development of multi-disciplinary research tools and methodologies. It discussed a step-by-step approach to operationalize complex notion of nostalgia through the practice of design and research.

The implementation process of co-creation method indicated that the certain sequence of activities helped participants to contribute valuably. Good/bad collage as the first step set the stage well by triggering group discussions and memories surrounding Mumbai's street foods. That aided participants to dive deeper into the lost recollections when they worked on India and Phoenix collages. Being creative was a challenge for some of the participants who were trained as engineers. Hence, after the first session, author had to strategize instructions and clues to stimulate imagination and creativity.

Food is a sensorial experience both when it's experienced and expressed. Hence, incorporating video data collection and analysis to trace meanings behind the animated actions and reactions was necessary for this research. Visual research and participatory sessions of co-creation were useful in operationalizing the concepts of memory and nostalgia. However, the interview and co-creation sessions went longer than anticipated because participants enjoyed talking about Mumbai's street foods and had a lot to share. 
The article presented here has proposed an approach to examine cultural artifacts of street foods by implementing rigorous and methodological processes. Such knowledge can be valuable for similar food studies and the development of innovative work related to research approaches and methodological instruments in the future.

\section{Acknowledgements}

Author is thankful to Prasad Boradkar and Eric Margolis for their guidance. This research is incomplete without the support of the participants and everyone else who contributed to this work.

\section{References}

Appadurai, Arjun. Modernity at Large: Cultural Dimensions of Globalization. University of Minnesota Press, 1996.

Baar, A. "Subaru Taps Nostalgia for the First Car." MediaPost.com, MediaPost, February 262012.

Boradkar, Prasad. "Design as Problem Solving." The Oxford Handbook of Interdisciplinarity, edited by Robert Frodeman et al., Oxford University Press, 2010, pp. 273-287.

Buchanan, Richard. "Wicked Problems in Design Thinking." Design Issues, vol. 8, no. 2, 1992, pp. 5-21, doi:https://doi.org/10.2307/1511637.

Chen, Yu-Jen. "Bodily Memory and Sensibility: Culinary Preferences and National Consciousness in the Case of "Taiwanese Cuisine"." Taiwan Journal of Anthropology, vol. 8, no. 3, 2010, pp. 163-196, doi:https://doi.org/10.7115/TJA.201012.0163.

Crowther, Gillian. Eating Culture: An Anthropological Guide to Food. University of Toronto Press, Higher Education Divisio, 2013.

du Gay, Paul et al. Doing Cultural Studies: The Story of the Sony Walkman. Sage Publications (in association with the Open University). 1997.

Friedman, Ken. "Towards an Integrative Design Discipline." Creating Breakthrough Ideas: The Collaboration of Anthropologists and Designers in the Product Development Industry, edited by Susan Squires and Byrne Bryan, Bergin and Garvey, 2002, pp. 200-214. 
Hanington, Bruce. "Methods in the Making: A Perspective on the State of Human Research in Design." Design Issues, vol. 19, no. 4, 2003, pp. 9-18, doi:https://doi.org/10.1162/074793603322545019.

Holroyd, Amy Twigger. "From Stitch to Society: A Multi-Level and Participatory Approach to Design Research." Design Issues, vol. 33, no. 3, 2017, pp. 11-24, doi:https://doi.org/10.1162/DESI a 00448.

Holtzman, Jon D. "Food and Memory." Annual Review of Anthropology, vol. 35, 2006, pp. 361-378, doi:https://doi.org/10.1146/annurev.anthro.35.081705.123220.

Huppatz, D. J. "Designer Nostalgia in Hong Kong." Design Issues, vol. 25, no. 2, 2009, pp. 14-28, doi:https://doi.org/10.1162/desi.2009.25.2.14.

Inda, Jonathan Xavier and Renato Rosaldo. The Anthropology of Globalization: A Reader. Blackwell Publishers, 2002.

Jones, Michael Owen and Lucy M. Long. Comfort Food: Meanings and Memories. University Press of Mississippi, 2017.

KTAR.COM. "Phoenix Found to Be among Least-Walkable Cities, but Is Improving." 2017.

Kumar, Vijay. 101 Design Methods: A Structured Approach for Driving Innovation in Your Organization. John Wiley \& Sons Inc, 2013.

Mankekar, Purnima. "India Shopping: Indian Grocery Stores and Transnational Configurations of Belonging." The Cultural Politics of Food and Eating: A Reader, edited by James L Watson and Melissa L Caldwell, Blackwell Pub, 2005, pp. 197214.

McCann, Willis H. "Nostalgia: A Descriptive and Comparative Study." The Pedagogical Seminary and Journal of Genetic Psychology, vol. 62, no. 1, 1943, pp. 97-104, doi:https://doi.org/10.1080/08856559.1943.10533859.

Ray, Krishnendu. The Migrants Table: Meals and Memories In. Temple University Press, 2004.

Rittel, Horst. "Some Principles for the Design of an Educational System for Design." Journal of Architectural Education, vol. 26, no. 1-2, 1971, pp. 16-27, doi:https://doi.org/10.1080/10464883.1971.11102482.

Sanders, Elizabeth and Pieter Jan Stappers. Convivial Toolbox How to Bring People We Serve Directly into the Design Process. BIS PUBLISHERS, 2012. 
Schiller, Nina Glick et al. "Towards a Definition of Transnationalism." Annals of the New York Academy of Sciences, vol. 645, no. 1, 1992, pp. ix-xiv, doi:https://doi.org/10.1111/j.1749-6632.1992.tb33482.x.

Seremetakis, C. Nadia. "The Senses Still: Perception and Memory as Material Culture in Modernity." Visual Anthropology Review, vol. 9, no. 2, 1993, pp. 1-18.

Steen, Marc et al. "Benefits of Co-Design in Service Design Projects." International Journal of Design, vol. 5, no. 2, 2011, pp. 53-60, http://index.ijdesign.org/index.php/IJDesign/article/view/890.

Sutton, David. "Cooking Skills, the Senses, and Memory: The Fate of Practical Knowledge." Food and Culture a Reader, edited by Carole Counihan and Penny Van Esterik, Routledge, 2013, pp. 299-319.

Weiler, Monica et al. "Co-Design: A Powerful Force for Creativity and Collaboration." 2016, https://medium.com/@thestratosgroup/co-design-a-powerful-force-forcreativity-and-collaborationbed1e0f13d46\#: :text=Conclusion, co\%2Dcreate $\% 20 \mathrm{a} \% 20 \mathrm{better} \% 20$ world.

Wilson, Janelle L. Nostalgia: Sanctuary of Meaning. Bucknell University Press, 2005.

Wilson, Stephanie and Lisa Zamberlan. "Design for an Unknown Future: Amplified Roles for Collaboration, New Design Knowledge, and Creativity." Design Issues, vol. 31, no. 2, 2015, pp. 3-15, doi:https://doi.org/10.1162/DESI a 00318.

Xue, Haian and Martin Woolley. "Design and Nostalgia: Idealized Memory and Strategic Design Innovation in China." The Journal of Design Strategies, vol. 6, no. 1, 2013, pp. 36-44. 


\section{Appendix}

Glossary of Foods

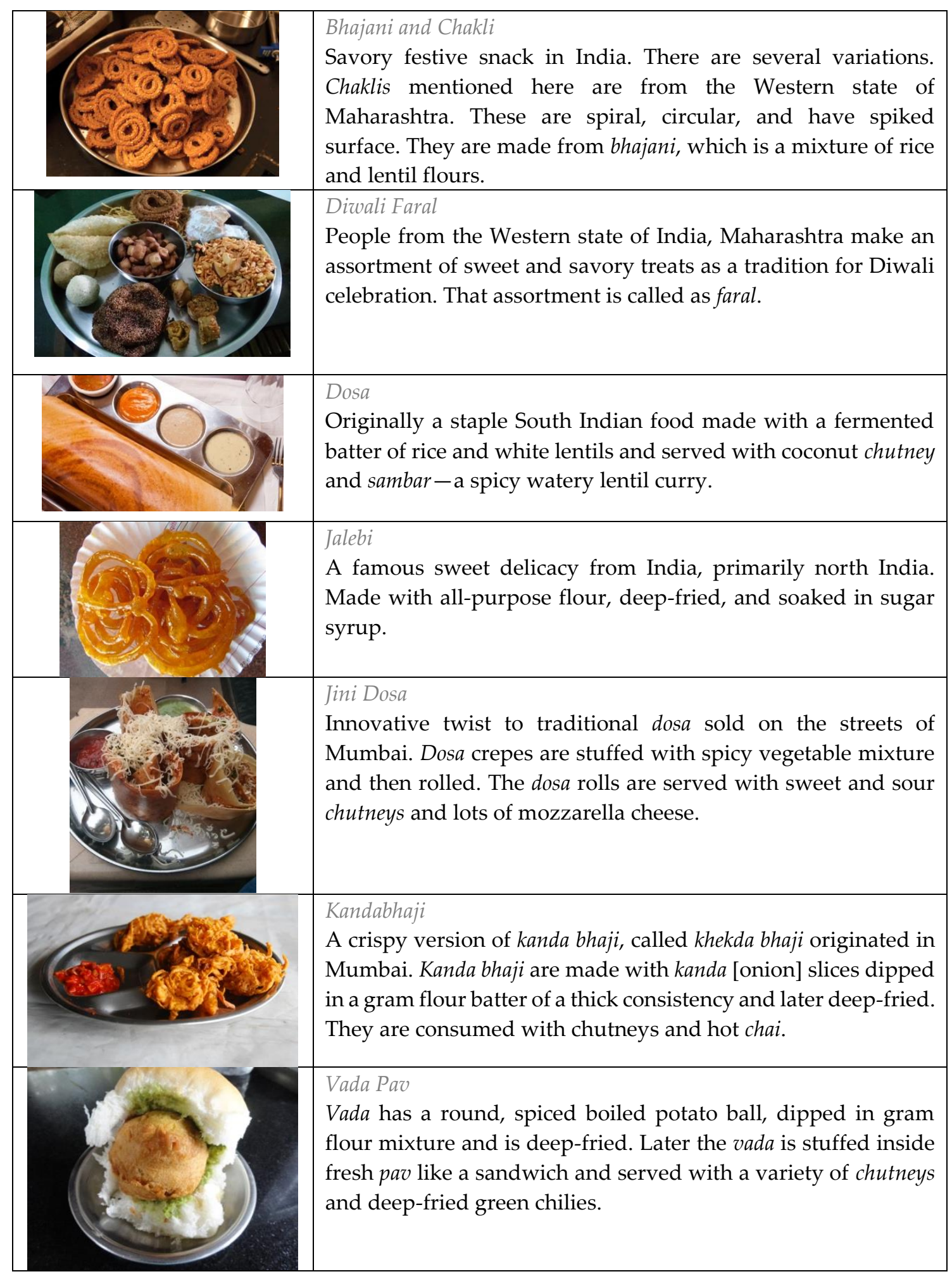

